
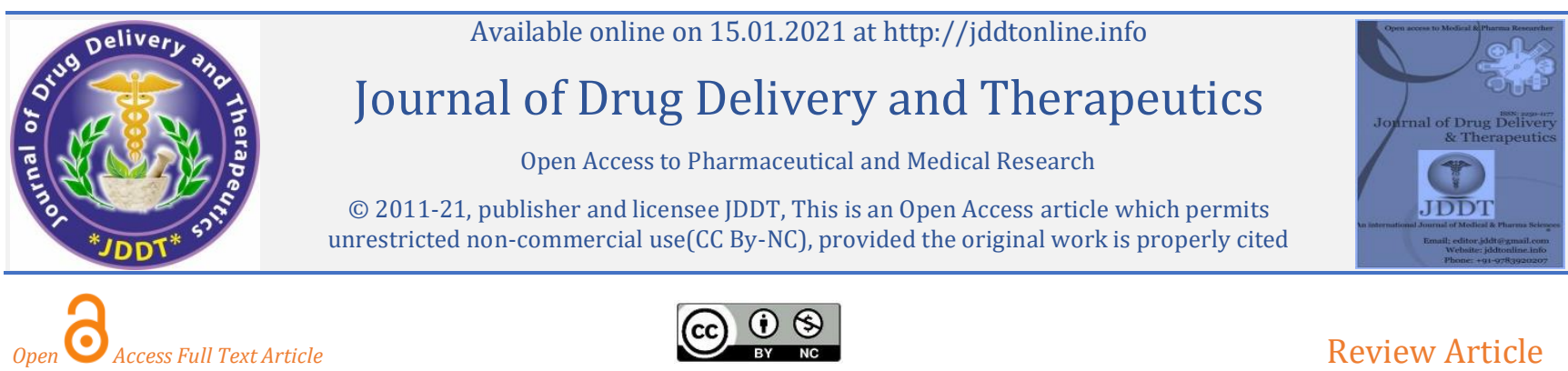

Review Article

\title{
A Review on Solubility Enhancement by Solid Dispersion Method
}

\author{
Laxmikant B. Dhande*1, Madhuri T. Deshmukh ${ }^{2}$, Abhijit N. Khopade ${ }^{2}$, Rajkumar V. Shete ${ }^{3}$, Vaibhavi V. Kunjir ${ }^{2}$ \\ ${ }^{1}$ M. Pharm. Student, Department of pharmaceutics, Rajgad Dnyanpeeth's College of Pharmacy, Bhor- 412206 Pune, Maharashtra, India \\ 2 Professor, Department of Pharmaceutics, Rajgad Dnyanpeeth's College of Pharmacy, Bhor- 412206 Pune, Maharashtra, India \\ ${ }^{3}$ Principal, Department of Pharmacology, Rajgad Dnyanpeeth's College of Pharmacy, Bhor- 412206 Pune, Maharashtra, India
}

\section{Article Info:}

\section{Article History:}

Received 08 Oct 2020;

Review Completed 18 Dec 2020

Accepted 29 Dec 2020;

Available online 15 Jan 2021

Cite this article as:

Dhande LB, Deshmukh MT, Khopade AN, Shete RV, Kunjir VV, A Review on Solubility Enhancement by Solid Dispersion Method, Journal of Drug Delivery and Therapeutics. 2021; 11(1):182-187

DOI: http://dx.doi.org/10.22270/jddt.v11i1.4489

\section{Abstract}

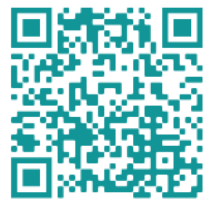

The issues of solubility for the targeted drug delivery of the new drug affects, the delivery many existing drug. The minimum $40 \%$ of the novel drug from the pharmaceutical industries are showing poor ability of solubilization in water. Hence to increase the solubility of such drug in waters and to increase their bioavailabilities are the major challenges to the scientists. So to overcome such problems and increase dissolution, development of solid dispersion with carriers having good water solubility is beneficiary. Hence solid dispersion methods are found to be an effective method to develop the solubility factor of the drug which showing poor solubility in water. The review highlights the various aspect of solid dispersion type, rational, advantages, limitation and manufacturing processes for the limited commercialization of solid dispersion.

Keywords: Solid dispersions, hydrophilic, carrier, solubility, polymer, bioavailability.

*Address for Correspondence:

Laxmikant B. Dhande, M. Pharm. Student, Department

of pharmaceutics, Rajgad Dnyanpeeth's College of

Pharmacy, Bhor- 412206 Pune, Maharashtra, India

\section{INTRODUCTION:}

The oral route is the most convenient and preferred method for administration of drug due to ease of administration and convenience. Because of a patient's prospective, oral route is a comfortable and a familiar means of taking medication 1 . Hence orally administrated medications are more effective when compared with other routes of administration. The minimum $40 \%$ of the novel drug from the pharmaceutical industries are showing poor capability of solubilization in water, because of slow release, slow dissolution and poor bioavailability which need to administration of large dose for producing desirable pharmacological effect ${ }^{2,7,8}$. To overcome these problems best option is solving solubility problem, enhancing solubility, dissolution rate of poor drugs which are water soluble by solid dispersion method. Hence solid dispersion is one of the best techniques. for enhancing the dissolution rate, solubility, and oral bioavailability of poor water-soluble drug. The two areas of pharmaceutical research that focus on improving oral bioavailability of active agent which includes enhancing solubility and dissolution rate of poorly water-soluble drug and enhancing permeability of poorly permeable drug,9. This narrative review focuses on the use of solid dispersion technique and method to improve the dissolution characteristics of poorly water- soluble drug and their oral bioavailability.

Table 1: BCS Classification System 3,10

\begin{tabular}{|l|l|l|l|}
\hline Class & Solubility & Permeability & Example of drug \\
\hline Class I & High Solubility & High Permeability & Benzapril, Loxoprofen, Sumatriptan etc. \\
\hline Class II & Low Solubility & High Permeability & Valsartan, Nimesulide, Lortadine, Aceclofenac, Glimepiride etc. \\
\hline Class III & High Solubility & Low permeability & Gabapentine, Topiramate, Atropine etc \\
\hline Class IV & Low Solubility & Low Permeability & Hydrochlorthiazide, Furesomide, Meloxicam etc. \\
\hline
\end{tabular}


Table 2: Materials used as carrier for solid dispersion 1,3

\begin{tabular}{|l|l|l|}
\hline Sr.no & Materials Used As Carrier & \multicolumn{1}{c|}{ Examples } \\
\hline 1 & Sugars & Dextrose, sucrose, galactose, sorbitol, maltose, xylitol mannitol, lactose \\
\hline 2 & Acids & Citric acid, succinic acid \\
\hline 3 & Polymeric materials & $\begin{array}{l}\text { Povidone (PVP), polyethylene glycol (PEG), hydroxypropyl methyl cellulose, } \\
\text { methyl cellulose, hydroxy ethyl cellulose, cyclodextrin, hydroxy propyl cellulose, } \\
\text { pectin, galactomannan }\end{array}$ \\
\hline 4 & Insoluble or enteric polymer & HPMC phthalate, eudragit L100, eudragit S100, Eudragit RL, Eudragit RS \\
\hline 5 & Surfactants & $\begin{array}{l}\text { Polyoxyethylene stearate, renex, poloxamer 188, texafor AIP, deoxycholic acid, } \\
\text { tweens, spans }\end{array}$ \\
\hline 6 & Miscellaneous & $\begin{array}{l}\text { Pentaerythritol, pentaerythrityl tetraacetate, urea, urethane, hydroxy alkyl } \\
\text { xanthins }\end{array}$ \\
\hline
\end{tabular}

\section{TYPE OF SOLID DISPERSION:3,11}

1) Eutectics

2) Amorphous solid solutions

3) Solid solution

a) Continuous solid solution

b) Discontinuous solid solution

c) Substitutional solid solution

d) Interstitial solid solution
4) Glass solution and suspension

\section{1) Eutectics Mixtures:}

A simple eutectic mixture consists of two compounds which are completely miscible in the liquid state but only to a very limited extent in the solid state. It is prepared by rapid solidification of fused melt of two components that show complete liquid miscibility but negligible solid-solid solution $\mathbf{3 , 1 1 , 1 2}$.

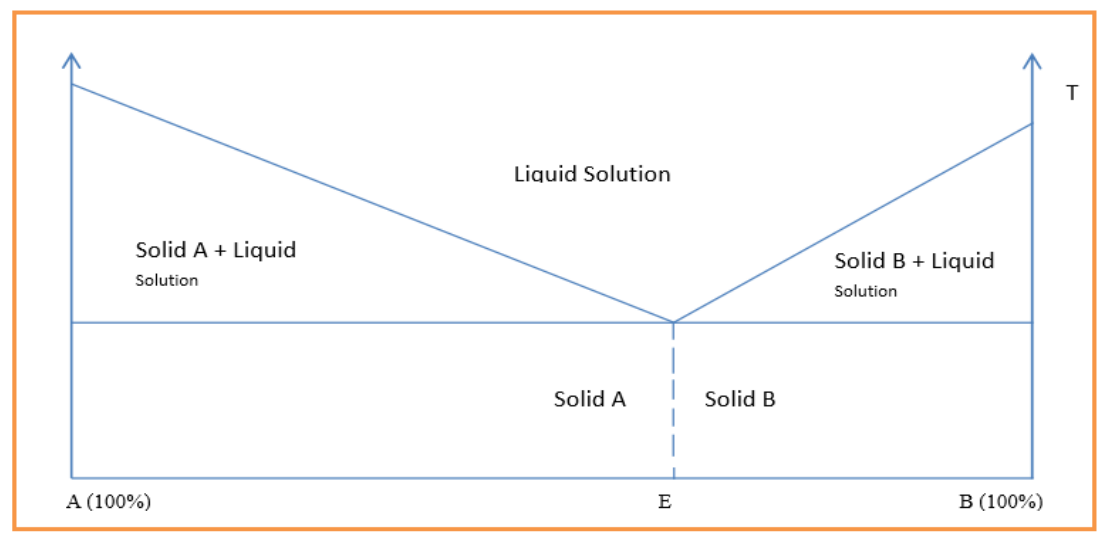

Figure 1: Eutectics mixtures

\section{2) Amorphous solid solution:}

This is similar to simple eutectic mixtures but only difference is that drug is precipitated out in an amorphous form ${ }^{3,13,14}$.

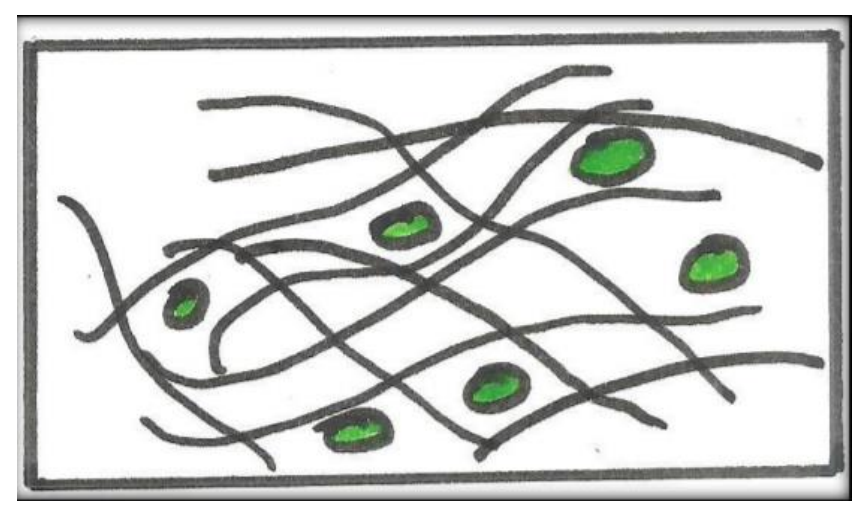

Figure 2: Amorphous solid solution

\section{3) Solid solution:}

Solid solutions are comparable to liquid solutions, consisting of just one phase irrespective of the number of components. In the case of solid solutions, the drug's particle size has been reduced to its absolute minimum viz. the molecular dimensions ${ }^{14}$ and the dissolution rate is determined by the dissolution rate of the carrier. Classified according to their miscibility (discontinuous solid solutions versus continous) or second, according to the way in which the solvate molecules are distributed in the solvendum (interstitial or amorphous, substitutional) ${ }^{3}$.

\section{a) Continuous solid solution:}

In a continuous solid solution, the components are miscible in all proportions. Theoretically, this means that the bonding strength between the two components is stronger than the bonding strength between the molecules of each of the individual components. Solid solutions of this type have not been reported in the pharmaceutical world till date ${ }^{3,5}$.

\section{b) Discontinuous solid solutions:}

In the case of discontinuous solid solutions, the solubility of each of the components in the other component is limited. Due to practical considerations it has been suggested by Goldberg et al.that the term solid solution' should only be applied when the mutual solubility of the two components exceeds $5 \%$. 


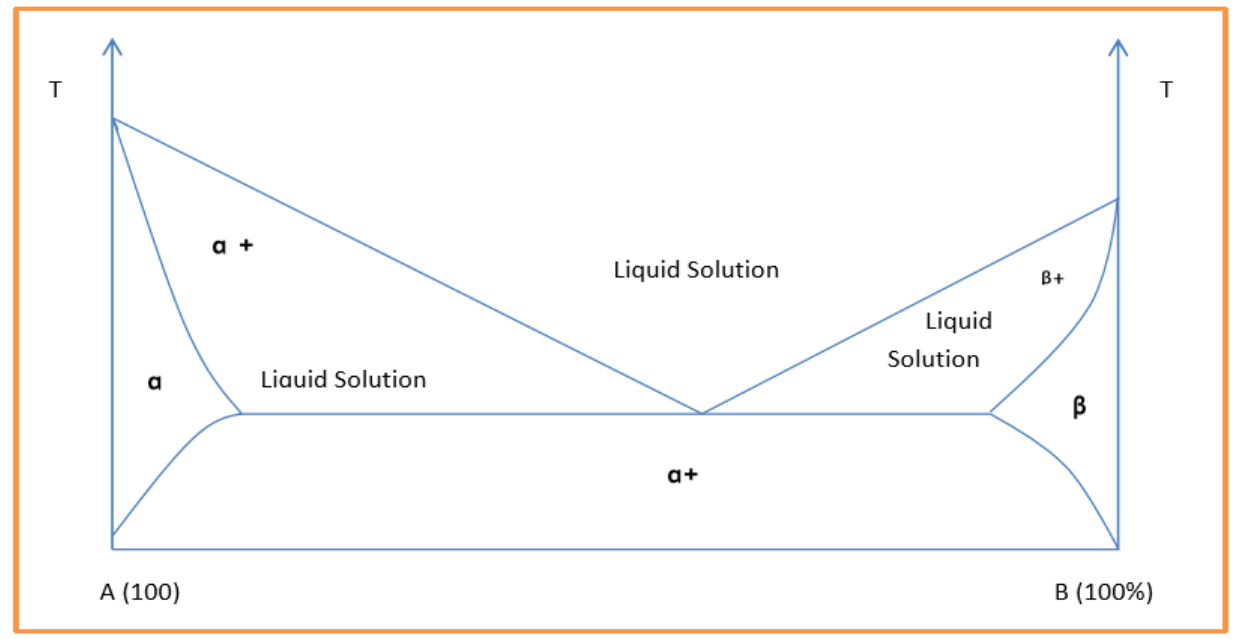

Figure 3: Discontinuous solid solution

\section{c) Subsitutional solid dispersions:}

Substitution is only possible when the size of the solute molecules differs by less than $15 \%$ or so from that of the solvent molecules15. Classical solid solutions have crystalline structure, in which the solute molecules can either substitute for solvent molecules in the crystal lattice or fit into the intrsticies between the solvent molecule ${ }^{3}$.

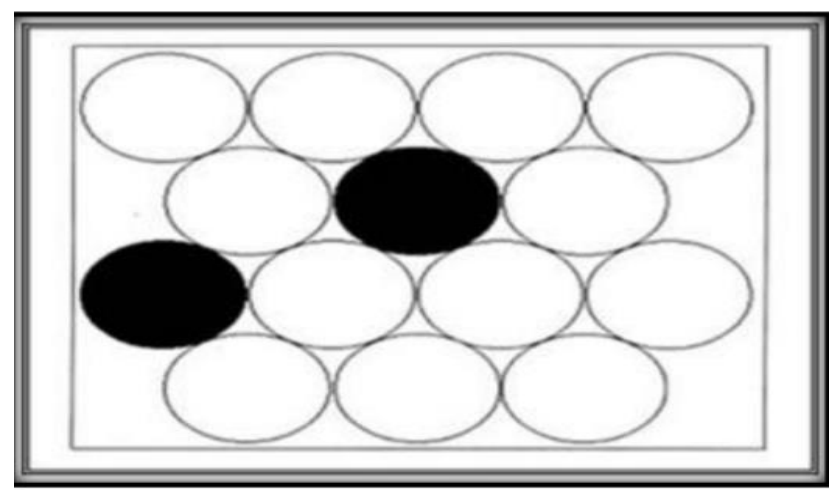

Figure 4: Subsitutional solid solution

\section{d) Interstitial solid solutions:}

In interstitial solid solutions, the dissolved molecules occupy the interstitial spaces between the solvent molecules in the crystal lattice. Solute molecule diameter should be less than 0.59 times than that of solvent molecular diameter ${ }^{3,5}$.

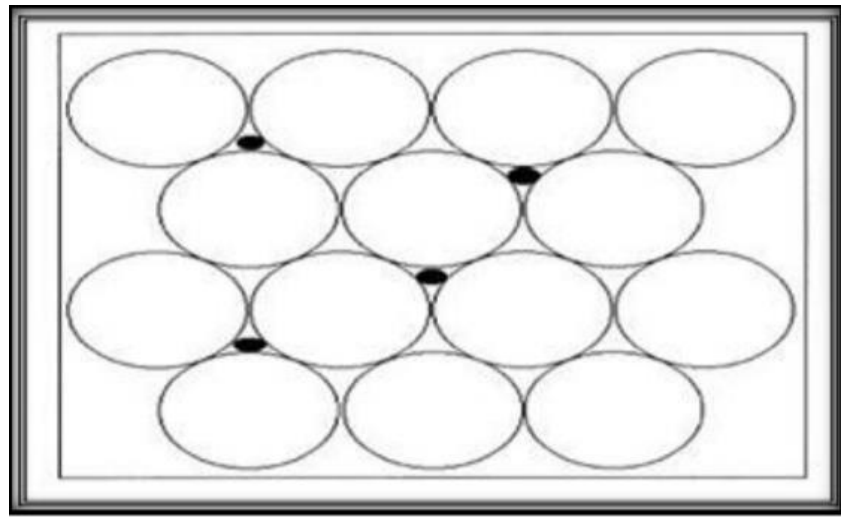

Figure 5: Interstitial solid solution

\section{4) Glass solution and suspensions:}

Glass solutions are homogeneous glassy system in which solute dissolves in glass carrier. Glass suspensions are mixture in which precipitated particles are suspended in glass solvent. Lattice energy is much lower in glass solution and suspension 3,5,14.

Solid Dispersion: Solid dispersion is defined as dispersion of one or more active ingredient inert carrier or matrix at solid state.

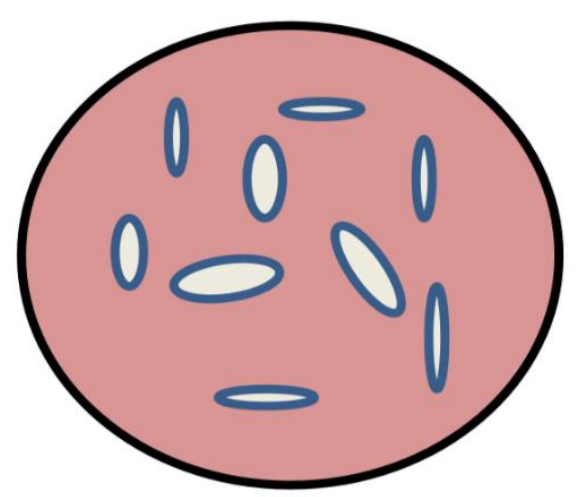

Figure 6: Solid dispersion of polymer matrix.

\section{ADVANTAGES OF SOLID DISPERSION:}

1) Reduced particle size:

As the solid dispersions are having smallest particle size state and after carrier dissolution the drug is dispersed in dissolution medium. The principle of solid dispersion can be applied by creating a mixture of a poorly water-soluble drug and highly soluble carriers. Hence bioavailability can be improved by forming a high surface area resulting in an increased dissolution.

2) Particles with Improved wettability:

The carrier increases the wettability properties of drug Carriers mainly influence the drug dissolution profile by direct dissolution or by co-solvent effects.

3) Particles with higher porosity:

In solid dispersion the particles has been found to have a higher degree of porosity. It depends upon the carrier 
properties. As solid dispersion containing linear polymer which produces larger and more porous particles than those containing reticular polymer which result in a higher dissolution rate. The increase in the porosity of solid dispersion particles increases the drug release profile.

4) Drugs in amorphous state:

The crystalline drug having poor water-soluble shows higher solubility when in the amorphous state. This can be achieved by using the drug in its amorphous state. Hence higher amorphous compositions can be obtained by choosing carriers, which exhibit specific interactions with them ${ }^{3}$.

\section{DISADVANTAGES OF SOLID DISPERSION:}

1. The undefined condition of medication may experience crystalline state, in this way poor soundness is the issue of strong scattering.

2. Handling issue show up because of thickness of some strong scatterings.

3. In nearness of dampness and extraordinary temperature strong scattering might be disintegrated, that can result in precious stone development.

\section{Shelf life forecast of indistinct material is troublesome.}

5. Hygroscopicity of polymers utilized in strong scattering retains dampness that can result in change of nebulous structure into crystalline form.

6. The instability is the major disadvantage of the solid dispersion. The deteriorating effect on solid dispersions such as moisture and temperature have more on physical mixture because of tackiness it is difficult for east handling of solid dispersion.

\section{APPLICATION:}

1) It is mainly applicable in obtaining homogeneous distribution of a small amount of drug in solid state.

2) It helps to stabilize the unstable drug16.

3) It is used to dispense both the liquid or gaseous compound in a solid dosage state.

4) The fast release primary dose can be formulated in a sustained dosage form.

5) It is also used to formulate sustained release of soluble drug by using poorly soluble or insoluble carrier.

6) By polymorph is given in solid dispersion system such as solid solution, eutectic mixture 3,17 .

\section{METHOD OF PREPARATION:4}

1) Melting method

2) Solvent evaporation method

3) Lyophilization technique

4) Melting solvent method

5) Melt extrusion method

6) Melt agglomeration process

7) Spray drying

8) Effervescent method

9) Electrospinning

10) Super critical fluid (SCF) Technology.

\section{1) Melting method:}

The melting and fusion method which involves the preparation of physical mixture of a drug and a watersoluble carrier and heated it directly until it melted. The mixture is melted first then solidified rapidly in an ice-bath under vigorous stirring. Then final solid mass is crushed, pulverized and sieving4.

\section{2) Solvent evaporation method:}

In this method the mixture such as drug and carrier is dissolved in a common solvent which is then evaporated until free film is lefts, Further dried and sieved²,18.

\section{3) Lyophilization technique:}

In this method transfer of heat and mass take place from the product under preparation. This technique was proposed as an alternative technique for the solvent evaporation. This is the type of a molecular mixing technique where the carrier and drug are co-dissolved by using common solvent. After this frozen and sublimed to obtain a lyophilization molecular dispersion ${ }^{2,4}$.

\section{4) Melting solvent method:}

In this method addition of fixed amount of solvent and then that solution is introduceded into melted from of polyethylene glycol below $70^{\circ} \mathrm{C}$. This method also used for thermolabile drug with high melting point. But limited drug is required with low therapeutic dose (below $50 \mathrm{mg}$ ) 2,4 .

\section{5) Melt extrusion method:}

This method meanly preferred for thermolabile drug. The drug and carrier are mixed together and typically processed with a twin -screw extrusion. The mixture is then simultaneously melted, homogenized and then extruded and shaped as tablets, granules, pellets, sheets, sticks or powder. The intermediates are then further processed into conventional tablets.3,4.

\section{6) Melt agglomeration process:}

In this method, the solid dispersion is prepared where the binder rols as a carrier. In addition to this, solid dispersion are prepared either by heating binder, drug and excipient to a temperature above the melting point of the binder ( melt in procedure ) or by spraying a dispersion of drug in molten binder on the heated excipient (spray-on procedure) by using a high shear mixer. A rotary processor is the alternative equipment for melt agglomeration. The rotary processer is mainly preferable for high melt agglomeration. Because it is easier to control the temperature and because a higher binder content can be incorporated in the agglomerates ${ }^{3,4}$.

\section{7) Spray drying:}

In this method accurately weight amount of drug and lipid carrier are dissolved in methanol to obtain clear solution. This solution is there sprayed on lab scale with the help of dryer, which result in the formation of solid dispersion. ${ }^{2}$

\section{8) Effervescent method:}

This is the method in which sodium bicarbonate and organic acid such as citric acid or succinic react with the each other to yield effervescence. But when combining of both that increased the dissolution and absorption rate of poor soluble drug2,18.

\section{9) Electrospinning:}

In this process solid fibers are produced from a polymeric fluid stream solution or melt delivered through a millimeter 
scale nozzle. It mainly involves the application of a strong electrostatic field over a conductive capillary attach to a reservoir containing a polymer solution or melt and a conductive collection screen. With increase in the electrostatic field strength up to but not exceeding a critical value, charge species which accumulated on the surface of a pendant drop, which destabilize the hemispherical shape in to a conical shape. Technique has much more potential for the production of nanofibers and controlling the release of biomedicine, It is simplest the cheapest technique utilized for the preparation of solid dispersion in further ${ }^{3,4,5}$.

\section{0) Super critical fluid (SCF) Technology:}

This is the super critical fluid anti-solvent technique, which involves the use of carbon dioxide as an anti-solvent for the solute.

After this solubilization of drug particles within supercritical fluid they may be recrystallized at great it reduced particle size. The flexibility and precision offered by supercritical fluid process allow micronization of drug particle, within narrow range of particle size obtained to sub-micro level. The current super critical fluid processes have the ability to demonstrate and to create nano-particular suspension of particle 5-2000 in the diameter. The spraying of the solution was done which is composed of the solute \& the organic solvent into a continuous super critical phase following concurrently. 4

\section{CHARACTERIZATION OF SOLID DISPERSION:}

Various methods for characterization of solid dispersion are mention below.

- Drug carrier miscibility

Hot stage microscopy

$>$ Powder x-ray diffractioon

$>$ NMR 1H spin lattice relaxation time

$>$ Differential scanning calorimetry

- Drug carrier interactions

$>$ Raman spectroscopy

$>$ Solid state NMR

$>$ FT-IR spectroscopy

- Physical structure

$>$ Dynamic vapor sorption

$>$ Inverse gas chromatography

> Scanning electron microscopy

$>$ Surface area analysis

$>$ Surface properties

- Amorphous content

$>$ Humidity stage microscopy

$>$ DSC(MTDSC)

$>$ ITC

$>$ Hot stage microscopy

$>$ Polarised light optical microscopy

$>$ Powder X-Ray diffraction

- Stability
$>$ Humidity studies

$>$ Isothermal Calorimetry

$>$ DSC (Tg, Temperature recrystallization)

$>$ Dynamic vapor sorption

$>$ Saturated solubility studies

- Dissolution enhancement

$>$ Intrinsic dissolution

$>$ Dynamic solubility

$>$ Dissolution

$>$ Dissolution in bio-relevant media. . $, 3,4^{2}$

\section{CONCLUSION:}

The method of solid dispersion is one of the effective approaches to enhance the solubility of poorly water soluble drug and to increase their bioavailability. Hence it is required to overcome some problems related to flow properties and stability of drug. Therefore the solid dispersion having synthetic or natural carrier which is low toxic, biocompatible and more easily available is an alternative and best choice for improving solubility of poorly water soluble BCS-II drug. The development of the release rate and oral bioavailability of poorly water-soluble drugs by using solid dispersion by careful choice of the carrier. It is also feasible to delay or slow down the release pattern of drug.

\section{REFERENCES:}

1) Dhirendra $\mathrm{K}$, Lewis S, Udupa $\mathrm{N}$ And Ati $\mathrm{K}$, "Solid dispersion: A Review" Pakistan journal of pharmaceutical sciences, 2009; 22(2): 234-246.

2) Shaikh SN, Hifzurrahman S, Athar MD, Dr. Khan GJ, Raza S, Mohd AA, "Review on solid dispersion of poor water soluble drug by using natural polymers" The Pharma innovation Journal 2019; 8(1):631-636.

3) Singh J, Walia M, Harikumar SL, Solubility enhancement by solid dispersion method: A Review, Journal of drug delivery \& therapeutics, 2013; 3(5):148-155.

4) Singh S, Baghel RS and Yadav L, "A review on solid dispersion" International journal of pharmacy \& life science 2011; 2(9):1078-1095.

5) Dixit ND, Niranjan SK. “A review: Solid dispersion" World journal of pharmacy and pharmaceutical science.2014; 3(9):238-257.

6) Sharma R, Mazumder R, Sharma A and Verma P: A review on: Solid dispersion" International journal of pharmacy \& life sciences. 2013; 4(7):2845-2854.

7) Argade PS, Magar DD, Saudagar RB. "Solid Dispersion: Solubility Enhancement Technique for poorly water soluble Drugs" Journal of Advanced Pharmacy Education \& Research. 2013; 3(4):427439.

8) Ratnaparkhi MP, Chaudhari PD. Solubility Enhancement of Poorly Water Soluble Drug Using Natural Carrier. International Journal of Life Science and Pharma Research, 2017; 7(3):9-18.

9) Leuner, C. and Dressman, J., Improving drug solubility for oral delivery using soliddispersions. Eur. J. Pharm. Biopharm, 2000; 47-60.

10) Amidon GL, Lennernas H, Shah VP, Crison JR, Theoretical basis for a biopharmaceutical drug classification: the correlation of in vitro drug product dissolution and in vivo bioavailability, Pharm Res, 1995; 2(3):413-420.

11) Sekiguchi K, Obi N, Studies on Absorption of Eutectic Mixture. I. A comparison of the behaviour of eutectic mixture of sulfathiazole and that of ordinary sulfathiazole in man, Chem. Pharm. Bull, 1961; 9:866-872.

12) Goldberg $\mathrm{AH}$, Gibaldi $\mathrm{M}$, Kanig JL, Increasing dissolutionrates and gastrointestinal absorption of drugs via solid solutions and eutectic mixtures II - experimental evaluation of a eutectic mixture: urea-acetaminophen system, J. pharm. Sci. 1966; 55:482-487. 
13) Castellan GW, Physical Chemistry, Addison-Wesley, Menlo Park, CA, 1983, 324-336.

14) Kumar B. Solid dispersion- A review, Pharma tutor.2017; $5(2): 24-29$.

15) Singh N and Sarangi MK. Solid dispersion-a novel approach for enhancement of bioavailability of poorly soluble drugs in oral drug delivery system, Global journal of pharmacy \& pharmaceutical science, 2017; 3(2):001-008.

16) Kamalakkannan V et al. Solubility enhancement of poorly soluble drugs by solid dispersion technique - A reviewJournal of Pharmacy Research 2010; 3(9):2314-2321.

17) Liu R, editor Water insoluble drug formulation. Library of Congress Cataloging-in- Publication Data; 2007.

18) Yadav B, Tanwar YS. Applications of solid dispersions. Journal of Chemical and Pharmaceutical Research. 2015; 7(2):965-978.

19) Bhaskar R, Monika OLA and Ravindra M. Ghongade. Review: Solid dispersion technique for enhancement of solubility of poorly soluble drug, Indian journal of pharmaceutical and biological research.2018; 6(2):43-52.

20) Rajeswari S, Bhanu K, Panda S, Swain RP, Ramana Murthy KV Kudamala S. Solid dispersion: An evergreen solubility enhancement technique for hydrophobic drugs, Journal of chemical and pharmaceutical research, 2016; 8(4):1218-1228.

21) Kumari B, Bishnoi HK. Solid dispersion: its type and mechanism of enhancement of solubility by solid dispersion, Journal of pharma Research, 2019; 8(3):65-71.

22) Nikam Shreya Pradeep. A Review: Increasing Solubility of Poorly Soluble Drugs, by Solid Dispersion Technique. Research J. Pharm. and Tech. 2011; 4(12):1933-1940.

23) Sneha D. Bhore. A Review on Solid Dispersion as a Technique for Enhancement of Bioavailability of Poorly Water Soluble Drugs. Research J. Pharm. and Tech. 2014; 7(12):1485-1491.

24) Punitha S, Srinivasa Reddy G, Srikrishna T, Lakshman Kumar M. Solid Dispersions: A Review. Research J. Pharm. and Tech. 2011; 4(3):331-334.

25) Divya B., Sabitha P., Ravindra Reddy, M. Kranthi Kumar Reddy, B.Narasimha Rao. An Approach to Enhance Solubility of Gatifloxacin by Solid Dispersion Technique. Asian J. Res. Pharm. Sci. 2012; 2(2):58-61.
26) Keerthi Manukonda, Rama Rao N, Santhosh Aruna M, Lakshmi Prasanna J. Solid Dispersions-An Approach to Enhance the Dissolution Rate of Clopidogrel Bisulphate. Asian J. Res. Pharm. Sci. 2014; 4(4):165-168.

27) Kolhe S, Chaudhari P, More D. Formulation and Evaluation of Solid Dispersion by Novel Technique. Asian J. Res. Pharm. Sci. 2013; 3(4):206-214.

28) Vakhariya RR, Kumbhar SM, Lade RB, Salunkhe PS, Ubale RH. Dissolution Rate Enhancement of Ramipril by Solid Dispersion Technique. Asian J. Pharm. Res. 2020; 10(1):08-12.

29) Reddy MKK, Rao BN, Reddy KR. Study on Effect of Excipients in Enhancing the Solubility of Nateglinide by Solid Dispersions . Asian J. Pharm. Res. 2012; 2(4):144-147.

30) Kolhe S, Chaudhari P, More D. Formulation Development of Solid Dispersion Prepared by Newer Approach: A Research. Asian J. Pharm. Res. 2013; 3(4):172-180.

31) Jadhav YL, Parashar B, Ostwal PP, Jain MS. Solid Dispersion: Solubility Enhancement for Poorly Water Soluble Drug. Research J. Pharm. and Tech. 2012; 5(2):190-197.

32) Giri TK, Mishra S, Tripathi DK. Carriers used for the development of solid dispersion for poorly water-soluble drugs. Research J. Pharm. and Tech. 2011; 4(3):356-366.

33) Ugandhar C. Formulation and Evaluation of Mesalazine Solid Dispersion. Research J. Pharm. and Tech. 5(6): June 2012; Page 809-812

34) Venkateswara Rao T, Vidyadhara S, Sambasivarao KRS Formulation and In-Vitro evaluation of Aceclofenac Controlled release tablets by wet granulation method and solid dispersion technique. Research J. Pharm. and Tech. 5(4): April 2012; Page 505-512.

35) Kumar KV, Arunkumar N, Varma PRP, Rani C, George N. Formulation and In Vitro Characterization of Valsartan Solid Dispersions. Research J. Pharm. and Tech. 2009; 2(3):502-506.

36) Choudhary H, Yadav B, Patel P, Das P, Pillai S. Formulation and Evaluation of Ramipril Fast Dissolving Tablet using Solid Dispersion. Research J. Pharm. and Tech 2019; 12(8):37643772.

37) Hajare AA, Shetty YT, Mali MN, Sarvagod SM. Characterization of Melt (Fusion) Solid Dispersions of Nifedipine. Research J. Pharm. and Tech. 2008; 1(3):230-234. 